Commentary

\title{
Sensorimotor Therapy Using Vestibular Stimulation: A Complementary Method for 'Treatment' of Developmental Coordination Disorder and a Possible Way to Awaken the Innate Potential for a Physically Active Life
}

Mats Niklasson ${ }^{1,}{ }^{*}$, Irene Niklasson ${ }^{1}$, Peder Rasmussen ${ }^{1,2}$

1. Center for Sensorimotor Research, Vestibularis Clinic, Kalmar, Sweden; E-Mails: mats.irene@vestibularis.se; irene@vestibularis.se; peder@vestibularis.se

2. Department of Neuroscience and Physiology, Institute of Child and Adolescent Psychiatry, Sahlgrenska University Hospital, Göteborg, Sweden

* Correspondence: Mats Niklasson; E-Mail: mats.irene@vestibularis.se

Academic Editor: Gerhard Litscher

Special Issue: Mind-Body Approaches that are Revolutionizing the Health Field

OBM Integrative and Complementary Medicine Received: August 15, 2021

2022, volume 7 , issue 1

Accepted: January 12, 2022

doi:10.21926/obm.icm.2201005

Published: January 29, 2022

\begin{abstract}
The aim of this commentary is to present characteristics of an "unidentified psychological barrier," which we previously have speculated to be associated with vestibular underachievement, an overlooked part for the understanding of the resistance to physical activity as well as in the assessments and interventions of developmental coordination disorder (DCD). Furthermore, we will discuss the importance of its identification and how to push knowledge forward. A delayed or partly absent sensorimotor development for an otherwise healthy infant might be a substantial sign of an underachieving vestibular system. It is time to act and to take sensorimotor immaturities seriously. In order to come to terms with DCD including physical inactivity there is a need for a grounded approach to sensorimotor development, not the least as a complement to already established 'treatment' methods.
\end{abstract} conditions of the Creative Commons by Attribution License, which permits unrestricted use, distribution, and reproduction in any medium or format, provided the original work is correctly cited. 


\section{Keywords}

Sensorimotor therapy; DCD; vestibular stimulation; vestibular dysfunction; primary reflexes; physical inactivity; physical activity; gravitational insecurity; gravitational security

\section{Introduction}

Physical inactivity is a global health problem with prevalence rates remaining almost the same over the last 25 years. It was estimated that in 2016 a quarter of the world's adult population were inactive and thereby put at a higher risk of premature mortality and of non-communicable diseases [1, 2]. Insufficient physical activity has also been estimated, globally, among $80 \%$ of adolescents $[3,4]$. Taken together this makes physical inactivity the fourth leading risk factor for a premature death. Not the least therefore, but also in order to meet both the World Health Organization (WHO)'s guidelines for Physical activity and their target of a global reducing of physical inactivity by $15 \%$ in 2030, research in different fields of movement science is of prime importance [5-7].

An Editorial in The Lancet 2013 [8] began, "Physical education is a divisive subject at school children seem to love it or hate it" and ended with, "Physical activity should be a priority for all schools, but, importantly, we must not allow children who do not excel in sport to drift or to be ignored. Children should associate positively with active behaviors early in life to carry and maintain a healthy relationship with physical activity through to adulthood".

The human body is made for movement and for physical activity. Why then is it so hard for some and apparently also connected with inconvenience? Bergman and Norlander concluded, in a qualitative study using a phenomenological perspective that the resistance could be due to an "unidentified psychological barrier". Participants had a desire to be more active but they were not able to break the vicious circle [9].

With this commentary our aim is to present further characteristics of this 'psychological barrier,' which we previously have speculated to be associated with vestibular underachievement, an overlooked part in the assessments and interventions of developmental coordination disorder (DCD) [10]. We will discuss the possibility that this by then 'identified psychological barrier' is of prime importance to understand in order for therapists, teachers and trainers to be able to increase the convenience of physical activity and to reduce the risks of developing DCD.

However, in order to get there we will start with a brief overview of DCD. Then we will continue with a very short presentation of sensorimotor therapy (SMT) according to the method Retraining for Balance (RB) which in turn will bring us to the overlooked importance of vestibular stimulation not only in the 'treatment' of DCD but also as a possible way to awaken the innate potential for physical activity. Lastly, we will sum up with some concluding remarks.

\section{Developmental Coordination Disorder}

DCD is defined as a neurodevelopmental disorder characterized by an immature and delayed gross and fine motor development without any obvious medical or intellectual cause. The prevalence among younger school children is reported to be $5-6 \%$. A diagnosis is given only if the 
motor skills impairment interferes significantly with the participation in, or performance of, daily activities at school, in the family or in social- and community life. Among younger children the delay might concern difficulties to accomplish gross motor milestones such as crawling and later walking. Clumsiness and problems with zipping pants and buttoning clothes are also common features. In the long run there might be improvements but it has been estimated that for 50 to $70 \%$ of the children the difficulties will remain through adolescence [11]. Evidently especially fine motor problems such as handwriting will affect schoolwork in general and a remaining clumsiness will certainly have a negative influence on physical education in particular [12]. There are increasing evidence for connections between DCD and internalizing problems, i.e. anxiety and depression [13]. The comorbidity with attention-deficit/hyperactivity disorder (ADHD) is also well known [14]. Despite the seriousness of the condition and its comorbidities, DCD is still not truly acknowledged within neither educational nor clinical practices $[15,16]$.

Although several approaches have been used there are not yet any 'gold standards' for assessments and interventions $[17,18]$. Approaches have mainly been labeled either as taskoriented or process-oriented. Task-oriented or top-down approaches focus on learning a certain motor performance, i.e. ' Neural Task Training' (NTT) and 'the Cognitive Orientation to daily Occupational Performance' (CO-OP). Process-oriented or bottom-up approaches aim at enhancing skills performance through improvement of body functions i.e. kinaesthetic training and sensory integration (SI).

In recent years there has been a tendency for the approaches to be partly mixed. In order to meet this change the European Academy of Childhood Disability (EACD) [19-21] has re-grouped the approaches into three new categories. The first category is oriented towards body function and structure aiming at identifying and improving underlying motor problems. The second category is activity-oriented, which means that an activity is designed with the aim to improve a certain performance. The final category is participation-oriented, aiming at designing an activity, which will enhance participation in every day life. Presently, in accordance with evidence based data, the EACD recommends category two and three, i.e., NTT and CO-OP as DCD interventions.

\section{Sensorimotor Therapy}

Sensorimotor therapy (SMT) according to the method 'Retraining for Balance' (RB) is processoriented and belongs by definition to the first category, as described above. SMT will on average take 36 months to complete and during that time the participant will spend approximately 15 minutes/day doing exercises with their parents (or concerning the adults, their spouse). In this way the child's caregivers are 'the therapists' who guarantees a safe and necessary proximity [2224]. Every eight weeks, after a careful re-assessment, a new part of the program will be introduced. The method has been thoroughly described elsewhere [25-29] and results have shown that the integration of aberrant primary reflexes, especially the Moro reflex, in combination with vestibular stimulation enhanced sensorimotor development among children as well as among adolescents and adults [25-28]. Results have also indicated that the process of SMT, using the instruments of RB, could be described in accordance with a conceptual kinesthetic-vestibular developmental model (KVDM) where the training induced temporary psychological and physical regressions, which were followed by transformations i.e. psychological and physical development $[26,30]$. 
Notwithstanding the improvements indicated in our studies [25, 27, 28] we cannot know for sure which level of remission [29] the participants have reached (see 4.2.4). In order to gain that knowledge we would have to conduct follow-up studies. Until we have reached better knowledge, the concept of 'treatment' has to be used with caution. Furthermore, Caçola and Lage argued that, as DCD is considered to be a condition that has no cure interventions can provide strategies, accommodations and skills to make life easier [15]. However, in our studies and in order to account for as sustainable results as possible the participants were left without training for at least 3 months before the final assessment $[25,27,28]$.

\section{Vestibular Function and Vestibular Stimulation}

\subsection{Introduction: A Short Update of Recent Publications}

"The sky's the limit for new ideas and developments in vestibular therapy (both pharmacological molecules and physical devices)" [31].

This citation was taken from an Editorial in 'Frontiers in Integrative Neuroscience' 2015, written as an introduction to a 'Research Topic' aiming at highlighting new discoveries in the field of vestibular cognition. In 2018 'Frontiers in Neurology' followed with another 'Research Topic', 'Vestibular contributions to health and disease' [32]. Obviously there is a growing interest in vestibular function, especially in its connection to cognitive development. One angle of interest is a possible link to dyscalculia $[33,34]$ another angle is a possible connection to psychological wellbeing [35].

In a recent publication dealing with 'sensory neuromodulation' the authors state that vestibular activity will affect all brain areas [36]. This is in accordance with the message given by Sailesh and colleagues who accounted for how the vestibular system, with its complex connections to different subcortical and cortical structures, controls different body functions in order to establish homeostasis. Their concluding remark was, "It is the need of time to start more translational research in this area to explore the potential benefits of vestibular stimulation" [37].

In 2020 'Frontiers in Psychology' published a 'Research Topic', 'Current perspectives in Developmental Coordination Disorder (DCD)', including 12 papers, none of which had a focus on vestibular function or primary reflexes. Beside our own publications, which could be regarded as exploratory and descriptive [25-28], this approach is rare. However, a recent small sample study from India concluded that vestibular stimulation had a positive impact on children diagnosed with DCD [38]. Considering the fact that vestibular activity affects not only the brain but also the whole human body ought to give us a reason to widen our perspective on ourselves as planetary individuals. Clark's concept of brain, body, and world interaction (BBWI) [39, 40] is a good starting point.

\subsection{Vertical and Horizontal Connections}

Elsewhere [29], one of us has extended the concept of BBWI to include both a vertical connection, i.e. the interaction between a human being and the gravitational force (here after gravity), and a horizontal connection, i.e. the ability to build friendships and to learn how to act in the world. Following the results from our studies our experience is that an increased downward 
connection i.e. improved vestibular function would in turn most likely enhance upward, i.e. cognitive, activity and connectivity.

The unchanging force of gravity is ever present on Earth and of absolute importance for the function of the whole human nervous system. During our whole life, through response from the vestibular system and its sensory receptors, gravity is the most trust worthy source for bringing energy to the nervous system [41, 42].

\subsubsection{Vertical Connection and 'Gravitational Insecurity'}

The vestibular nuclei appear around the $9^{\text {th }}$ week after conception and are functional by the $11^{\text {th }}$ week $[43,44]$. Except for interoceptive sensory receptors the vestibular system is the only sensory system to be mature by the $21^{\text {st }}$ week $[45,46]$. While some researchers like Windle [47] and Prechtl [48] argue that the system is inhibited during pregnancy others like Odent [49] and Restak [50] hold that the foetus, while floating, is constantly stimulated by the mother's movements. It is due to its early maturation and to stimulation that the vestibular system is regarded to be of great importance for brain development [44]. After birth, during infancy, especially between 6 and 12 months the vestibular system is very responsive $[51,44]$. This period coincides with the time for the development of tummy crawling, creeping on hands and knees and the hardship to master gravity in an up-right position i.e. walking [52]. Then there is a rather rapid decline in vestibular sensitivity until 2.5 years of age followed by a gradual decline until puberty, which is in line with what could be understood from Paul Schilder (1886-1940) when he more or less explicitly suggested an addition to Freud's classical oral and genital stages, a gravitational stage, operative for another 10 to 15 years. According to Schilder, that is how long it would take to defy gravity in order to fully develop coordinated motor skills. This new stage would also have influence on both an orderly and sequential development of logic and on the development of personality [53].

Schilder was one of the first researchers to study psychological implications in connection with the vestibular system. He found that organic changes in the vestibular system affected both body attitudes and psychic structures, which in turn influenced perception. Schilder concluded that this finding could open up this area for studies of neuroses and psychoses and their relation to the vestibular system [54].

Early in the $20^{\text {th }}$ century Joel E. Goldthwait (1866-1961) and his colleagues at Harvard University laid an important physiological and medical foundation for what later came to be modern movement therapies. They examined the human body and its relation to gravity and following their results, they asked people to pay better attention to how they move and hold their body in relation to gravity $[55,56]$.

Ida Rolf (1896-1979) who knew about the work of Goldthwait came to be known for the concepts of 'Structural integration' or 'Rolfing'. Her work focused on both the clinical and the physiological importance of gravity and she held that any misalignment would affect the whole system. A variety of somatic and psychological states could be addressed by restoring verticality $[23,56,57]$. 


\subsubsection{Horizontal Connection and 'Gravitational Security'}

Still another aspect of the vestibular-gravity connection is to be found with Ayres and Robbins [58] who wrote that the human relationship to gravity is more primal than the relationship between mother and child. They stressed the importance of building a 'gravitational security', which is the result of the integration of the vestibular system and gravity. In our daily life we take both gravity and 'gravitational security' for granted because they are so fundamental, but a firm connection to Earth i.e. gravity is the foundation on which we build interpersonal relationships. Without a safe relation to gravity all horizontal relations will suffer. Not even the most loving mother is able to fully reach her child if the Earth is no safe place to be. Children with vestibular problems will behave as if they were lost in space.

Gilfoyle and colleagues articulated a similar view and used the concept 'spatiotemporal stress' to describe a distress connected to an altered sensorimotor integrative process which could affect both the child's progress toward maturity and its relationships within the family as well as to the world outside [59].

Also studies by a fourth person are of interest when it comes to 'gravitational security,' namely Paul Schilder. As early as in the first quarter of the $20^{\text {th }}$ century he wrote [60], although not published until 1964, "The child should not be exposed to threats concerning his motor security without having reassurance" (p.169), connecting the primal fear of falling, insecurity and anxiety to the loss of equilibrium, to the Moro reflex (see section 3). This reflex was first described in 1918 by Ernst Moro. Its phylogenetic meaning is still unclear but the reflex is detectable at approximately week 30 in utero and is supposed to be suppressed during the first six months postnatally. The Moro reflex is most probably mediated by vestibular nuclei and has a close connection to the grasp reflex [61], mentioned also by Feldenkrais who like Schilder referred to our inborn fear of falling as well as to the vestibular systems role in anxiety [62].

\subsubsection{Connection between the Vestibular System and Some Primary Reflexes}

Neither can we take our fundamental relation to gravity for granted nor the suppression of some primary reflexes. This experience has also been strongly indicated in our previous studies [25-28].

Primary reflexes are supposed to be suppressed at around 6 months postnatally, which is also the time for the development of tummy crawling and a couple of months later even for creeping on hands and knees. These are gross motor milestones of prime importance not only for coordination but also for hip and trunk stability, both of which are essential for a stable up-right posture. The human body is indeed badly suited for standing [62]. The body has to be well prepared and then well kept, because to defy gravity will become a life long struggle.

\subsubsection{Not neither - nor, rather a Continuum}

From our point of view the presence or absence of primary reflexes as well as of vestibular function are not questions of neither nor, rather, there is a continuum. Over the lifespan we can, most probably, expect oscillations back and forth within the frames of this continuum. This is one reason why it is important to keep the concept of remission in mind (see section $\mathbf{3}$ ). 
Capute and Accardo [52] used the concept of 'primary reflex suppression,' which implies that the primary reflexes have to be put under cortical control but they will all the same remain within the lower parts of the nervous system in order to reappear in urgent situations [63], or when we are getting older and our cognitive functions decline. In this way the primary reflexes could be viewed as 'lifelines' and as a 'survival kit'. We have argued that a receptive vestibular system is a prerequisite for a proper vestibular function, in order for the primary reflexes to become suppressed, thereby allowing the gross motor milestones to develop. This in turn will prepare the human body for a stable erect position as well as for sensorimotor coordination e.g., [10].

\subsubsection{Physical Activity as a Part of a DCD Context}

In order to reach a consistent use of the term DCD and to avoid confusion it has been recommended that any new proposed subtype or inclusion should be introduced within the context of DCD [64]. The concept 'Environmental stress hypothesis' was coined by Cairney and colleages in 2010 [65], aiming to emphasize the role of different negative stressors on children with DCD. The hypothesis was later extended to include also lower levels of physical activity as a factor, which could connect DCD to internalizing problems in children [66]. In accordance with the hypothesis, Caçola and Lage suggested that interventions for DCD should include both psychosocial wellbeing and part taking in physical activities [15]. This sounds very good but what if you know that physical activity would be good for you but still you cannot put yourself together to break the vicious circle [9].

It was recently suggested that an emphasizing of the benefits from physical activities on mental wellbeing would send a meaningful message to adolescents [67]. Such a message sounds also good but if there is a 'psychological barrier' we don't think it would help. Providing information is not enough.

\subsubsection{Vestibular 'Underachievement' - an 'Identified Psychological Barrier'}

Building on the results from our studies [25-28] we suggested an approach stressing the importance of 'grounded assessments and interventions' to become a part of the DCD context [10]. This approach uses vestibular stimulation as a vital part of the intervention. Vestibular stimulation has so far been overlooked both in regard to physical inactivity and as a complement in the 'treatment' of DCD. However, our studies have indicated its importance as a mediator of physical inactivity into physical activity. Results of a qualitative study aiming at understanding the process of SMT showed, "In several cases the children showed a much greater interest in physical activity. When the children felt in control of their body, they enjoyed both physical education and sports outside school more". "My child participates more actively. He is not just present" (quotation from a parent). "Some children occasionally felt a need for muscular exertion and then appeared to enjoy combat sports. When their legs cooperated, they found it easier to run and dribble, and soccer then became more attractive" [26] (p. 338).

We propose that the awakened interest in physical activity is due to an increased vestibular receptivity and to the suppression of primary reflexes. The enhancement of vestibular function i.e. reducing vestibular dysfunction will contribute to the breaking of an 'identified psychological barrier' and the vicious circle it had created [9], which in turn also, most probably, will affect psychological wellbeing in a positive way. 


\subsubsection{Physical Activity is Also a Part of a Continuum}

We are well aware of the fact that sensorimotor difficulties are not the only reasons for physical inactivity and also that the level of activity can fluctuate from person to person, from day to day depending on the circumstances e.g., [68-70]. However, when foremost children are physically inactive we have to find out why.

\section{Concluding Remarks}

The aim of this commentary was to present characteristics of an "unidentified psychological barrier", which we previously have speculated to be associated with vestibular underachievement, an overlooked part for the understanding of the resistance to physical activity as well as in the assessments and interventions of developmental coordination disorder (DCD). Then to further discuss the importance of its identification and how to push knowledge forward.

Our studies have shown that an underachieving but otherwise obviously uninjured vestibular system appears to require stimulation in order to re-establish the aim of its function. From this it follows that an infant's sensorimotor development has to be closely monitored and not taken for granted.

Previous studies have shown that sensorimotor difficulties do not disappear with age $[14,27]$ rather, in early puberty, movement patterns become more adult like [27, 71, 72]. In order to avoid further difficulties for the child, sensorimotor deviations have to be taken seriously as soon as possible [15].

We would like to encourage parents to use slow and smooth vestibular stimulation with their infants e.g., [44] and stay observant on the suppression of primary reflexes as well as on the development of motor milestones such as tummy crawling and creeping on hands and knees [52]. A delayed or partly absent sensorimotor development for an otherwise healthy infant might be a strong enough sign of an underachieving vestibular system. The significance of an aberrant Moro reflex beyond 6 months of age should not the least be an adequate reason for further enquiry. For this to become possible the medical establishment has to be ready to meet this challenge $[15,16$, 73, 74].

It is time to act and to take sensorimotor immaturities seriously. In order to come to terms with DCD including physical inactivity there is a need for a grounded approach to sensorimotor development not the least as a complement to already established 'treatment' methods.

\section{Ethical statement}

This Commentary followed the ethical standards of the World Medical Association's Declaration of Helsinki concerning Ethical Principles of Medical Research involving Human Subjects and in accordance with the Swedish of Ethics.

\section{Acknowledgement}

We would like to honor the memory of our former coauthor and mentor Professor Torsten Norlander who sadly passed away in 2020. We have missed him deeply during the process of writing this manuscript. 


\section{Author Contributions}

Mats Niklasson, main responsibility for the writing of the manuscript. Irene Niklasson, contributing theoretical aspects and proof reading during the whole process. Peder Rasmussen, medical advice and proof reading.

\section{Funding}

None.

\section{Competing interests}

The authors declare that the research was conducted in absence of any commercial or financial relationship that could be construed as a potential conflict of interest.

\section{References}

1. The Lancet. A sporting chance: Physical activity as part of everyday life. Lancet. 2021; 398: 365.

2. Hallal PC, Pratt M. Physical activity: Moving from words to action. Lancet Glob Health. 2020; 8: E867-E868.

3. van Sluijs EM, Ekelund U, Crochemore-Silva I, Guthold R, Ha A, Lubans D, et al. Physical activity behaviours in adolescence: Current evidence and opportunities for intervention. Lancet. 2021; 398: 429-442.

4. Guthold R, Stevens GA, Riley LM, Bull FC. Global trends in insufficient physical activity among adolescents: A pooled analysis of 298 population-based surveys with 1.6 million participants. Lancet Child Adolesc Health. 2020; 4: 23-35.

5. Tremblay MS. Challenges in global surveillance of physical activity. Lancet Child Adolesc Health. 2020; 4: 2-3.

6. World Health Organization. WHO 2020 guidelines on physical activity and sedentary behavior[Internet]. Geneva: World Health Organization; 2020 [cited date 2021 July 29]. Available from: https://apps.who.int/iris/bitstream/handle/10665/336656/9789240015128eng.pdf.

7. Ding D, Mutrie N, Bauman A, Pratt M, Hallal PR, Powell KE. Physical activity guidelines 2020: Comprehensive and inclusive recommendations to activate populations. Lancet. 2020; 396: 1780-1782.

8. The Lancet. Ready, set, go for physical activity. Lancet. 2013; 381: 1960.

9. Bergman A, Norlander T. "Hay sacks anonymous": Living in the shadow of the unidentified. Psychological aspects of physical inactivity from a phenomenological perspective. Qual Rep. 2005; 10: 795-816.

10. Niklasson M, Rasmussen P, Niklasson I, Norlander T. Developmental coordination disorder: The importance of grounded assessments and interventions. Front Psychol. 2018; 9: 2409.

11. American Psychiatric Association. Diagnostic and statistical manual of mental disorders. 5th ed. Arlington: American Psychiatric Association; 2013. pp.74-77.

12. Harrowell I, Hollén L, Lingam R, Emond A. The impact of developmental coordination disorder on educational achievement in secondary school. Res Dev Disabil. 2018; 72: 13-22. 
13. Omer S, Jijon AM, Leonard HC. Research review: Internalising symptoms in developmental coordination disorder: A systematic review and meta-analysis. J Child Psychol Psychiatry. 2019; 60: 606-621.

14. Rasmussen P, Gillberg C. Natural outcome of ADHD with developmental coordination disorder at age 22 years: A controlled, longitudinal, community based study. J Am Acad Child Adolesc Psychiatry. 2000; 39: 1424-1431.

15. Caçola P, Lage G. Developmental Coordination Disorder (DCD): An overview of the condition and research evidence. Motriz Rev Educ Fis. 2019; 25: e101923.

16. Gillberg C. Deficits in attention, motor control, and perception: A brief review. Arch Dis Child. 2003; 88: 904-910.

17. Sankar G, Monisha R. Life impact of developmental coordination disorder: Qualitative analysis of patient and therapist experiences. Biomed Pharmacol J. 2019; 12: 491-494.

18. Smits-Engelsman BC, Blank R, van der Kaay AC, Mosterd-van der Meijs R, Vlugt-van den Brand $E$, Polatajko $H J$, et al. Efficacy of interventions to improve motor performance in children with developmental coordination disorder: A combined systematic review and meta-analysis. Dev Med Child Neurol. 2012; 55: 229-237.

19. Blank R, Barnett AL, Cairney J, Green D, Kirby A, Polatajko H, et al. International clinical practice recommendations on the definition, diagnosis, assessment, intervention, and psychosocial aspects of developmental coordination disorder. Dev Med Child Neurol. 2019; 61: 242-285.

20. Dan B. Developmental coordination disorder continues to evolve. Dev Med Child Neurol. 2019; 61: 240.

21. Newman CJ. Clinical guidelines in neurodevelopmental disorders: Following the line. Dev Med Child Neurol. 2019; 61: 241.

22. Mahoney G, Perales F. The role of parents in early motor intervention. Downs Syndr Res Pract. 2006; 10: 67-73.

23. Oschman J. Energy medicine in therapeutics and human performance. London: Butterworth Heinemann; 2009. pp.75, 281-295.

24. Zohar D. The quantum self. London: Flamingo; 1991. pp.107-122.

25. Niklasson M, Niklasson I, Norlander T. Sensorimotor therapy: Using stereotypic movements and vestibular stimulation to increase sensorimotor proficiency of children with attentional and motor difficulties. Percept Mot Skills. 2009; 108: 643-669.

26. Niklasson M, Niklasson I, Norlander T. Sensorimotor therapy: Physical and psychological regressions contribute to an improved kinesthetic and vestibular capacity in children and adolescents with motor difficulties and concentration problems. Soc Behav Pers. 2010; 38: 327-346.

27. Niklasson M, Rasmussen P, Niklasson I, Norlander T. Adults with sensorimotor disorders: Enhanced physiological and psychological development following specific sensorimotor training. Front Psychol. 2015; 6: 480.

28. Niklasson $M$, Norlander T, Niklasson I, Rasmussen P. Catching-up: Children with developmental coordination disorder compared to healthy children before and after sensorimotor therapy. PLoS ONE. 2017; 12: e0186126.

29. Niklasson M. The importance of grounded assessments and interventions: Towards a new framework for developmental coordination disorder. Bolton: Bolton University; 2020. 
30. Ho MW. The rainbow and the worm: The physics of the organisms. London: World Scientific Publishing Co; 2005. pp.79-94.

31. Besnard S, Lopez C, Brandt T, Denise P, Smith PF. Editorial: The vestibular system in cognitive and memory process in mammalians. Front Integr Neurosci. 2015; 9: 55.

32. Cohen B, Lewis R. Editorial: Vestibular contributions to health and disease. Front Neurol. 2018; 9: 117.

33. Moser I, Vibert D, Caversaccio MD, Mast FW. Impaired math achievement in patients with acute vestibular neuritis. Neuropsychologia. 2017; 107: 1-8.

34. Smith PF. Dyscalculia and vestibular function. Med Hypotheses. 2012; 79: 493-496.

35. Brandt T, Dieterich M. 'Excess anxiety' and 'less' anxiety': Both depend on vestibular function. Curr Opin Neurol. 2020; 33: 136-141.

36. Black RD, Rogers LL. Sensory neuromodulation. Front Syst Neurosci. 2020; 14: 12.

37. Sailesh GK, Ravikanth M, Arun HS. Effect of vestibular stimulation on different body systems: A overview. J Med Sci Health. 2018; 4: 1-10.

38. Ganapathy SU, Monisha R, Amalraj Vallaba Doss C, Palanivel RM. Effectiveness of vestibular stimulation in children with developmental coordination disorder. Asian J Pharm Clin Res. 2020; 13: 37-39.

39. Clark A. Being there: Putting brain, body and world together. Cambridge, MA: The MIT Press; 1997.

40. Clark A. An embodied cognitive science? Trends Cogn Sci. 1999; 3: 345-351.

41. Hydén H. Biochemical aspects of brain activity. In: Man and civilization: Control of the mind. New York, NY: McGraw-Hill; 1961. pp.18-41.

42. Stanley-Jones D, Stanley-Jones K. The kybernetics of natural systems. A study in patterns of control. London: Pergamon Press; 1960. pp.60.

43. Humphrey $T$. The embryologic differentiation of the vestibular nuclei in man correlated with functional development. In: Vestibular and oculomotor problems: Extraordinary meeting of the Japan society of vestibular research. Tokyo: University of Tokyo; 1965. pp.51-56.

44. Piontelli A. Development of normal fetal movements. The last 15 weeks of gestation. Milan: Springer; 2015. pp.119-121.

45. Larsen WJ. Human embryology. London: Churchill Livingstone; 1993. pp.382-383.

46. Robbins J. Vestibular integration: Man's connection to the earth. Somatics. 1977; 1: 27-36.

47. Windle WF. Physiology of the fetus: Relation to brain damage in the perinatal period. Springfield, IL: Charles C. Thomas Publisher; 1971. pp.78.

48. Prechtl HF. Continuity and change in early neural development. In: Continuity of neural functions from prenatal to postnatal life. Oxford: Spastics International Medical Publications; 1984. pp.1-15.

49. Odent M. Primal health. A blueprint for our survival. London: Century Hutchinson Ltd; 1986. pp.18-30.

50. Restak RM. The brain. The last frontier. New York, NY: Warner Books; 1979. pp.122.

51. Ornitz EM. Normal and pathological maturation of vestibular function in the human child. In: Development of auditory and vestibular systems. New York, NY: Academic Press, Inc; 1983. pp.479-536.

52. Capute AJ, Accardo PJ. Developmental disabilities in infancy and childhood. Baltimore, MD: Paul H. Brookes Co., Inc; 1991. pp.20-21, 341. 
53. Hubbard DG, Wright CG. The emotion of motion. Functions of the Vestibular apparatus. In: Paul Schilder: Mind explorer. New York, NY: Human Sciences Press; 1984. pp.161-182.

54. Schilder P. Mind: Perception and thought in their constructive aspects. Freeport, NY: Books for Libraries Press; 1942/1971. pp.85.

55. Goldthwait JE, Brown LT, Loring TS, Kuhns JG. Body mechanic in the study and treatment of disease. Philadelphia, NJ: J.B Lippincott Company; 1937.

56. Oschman JL. Energy medicine: The scientific basis. London: Churchill Livingstone; 2008. pp.147-163, 165-174.

57. Rolf IP. Structural integration. Gravity: An unexplored factor in a more human use of human beings. J Inst Compar Study History Philos Sci. 1962; 1: 3-20.

58. Ayres AJ, Robbins J. Sensory integration and the child: Understanding hidden sensory challenges. 25th ed. Los Angeles, CA: Western Psychological Services; 2005. pp.69-70.

59. Gilfoyle EM, Grady AP, Moore JC. Children apt. Thorofare, NJ: SLACK Incorporated; 1990. pp.13-32.

60. Schilder P. Contributions to developmental neuropsychiatry. New York, NY: International Universities Press, Inc; 1964. pp.161-209.

61. Futagi $Y$, Toribe $Y$, Suzuki $Y$. The grasp reflex and Moro reflex in infants: Hierarchy of primitive reflex responses. Int J Pediatr. 2012; 2012: 191562. doi: 10.1155/2012/191562.

62. Feldenkrais M. Body and mature behaviour. Tel-Aviv, Israel: ALEF Ltd; 1988. pp.66-79, 83-94.

63. Blythe SG. Attention, balance, and coordination: The A.B.C. of learning success. Chichester, UK: John Wiley \& Sons Ltd; 2009. pp.101-102.

64. Magalhães LC, Missiuna C, Wong S. Terminology used in research reports of developmental coordination disorder. Dev Med Child Neurol. 2006; 48: 937-941.

65. Cairney J, Veldhuizen S, Szatmari P. Motor coordination and emotional - behavioral problems in children. Curr Opin Psychiatry. 2010; 23: 324-329.

66. Cairney J, Rigoli D, Piek J. Developmental coordination disorder and internalizing problems in children: The environmental stress hypothesis elaborated. Dev Rev. 2013; 33: 224-238.

67. Matias TS, Piggin J. Physical activity promotion: Can a focus on disease limit successful messaging? Lancet. 2020; 8: E1263.

68. Dumid D, Olds T, Sawyer SM. Moving beyond more: Towards a healthy balance of daily behaviours. Lancet. 2021; 398: 373-374.

69. Martin Ginis KA, van der Ploeg HP, Foster C, Lai B, McBride CB, Ng K, et al. Participation of people living with disabilities in physical activity: A global perspective. Lancet. 2021; 398: 443455.

70. Pereira AM, Verhagen E, Figueiredo P, Seabra A, Martins A, Brito J. Physical activity levels of adult virtual football players. Front Psychol. 2021; 12: 596434.

71. Teicher JD. Preliminary survey of motility in children. J Nerv Ment Dis. 1941; 94: 277-304.

72. Peters JE, Romine JS, Dykman RA. Special neurological examination of children with learning disabilities. Dev Med Child Neurol. 1975; 17: 63-78.

73. Gillberg C, Kadesjö B. ADHD with developmental coordination disorder. In: ADHD comorbidities: Handbook for ADHD complications in children. Arlington, VA: American Psychiatric Publishing, Inc; 2009. pp.305-314.

74. Gillberg C, Rasmussen P. To what extent are learning and behavioural problems brain related? Acta Psychiatr Scand. 2003; 108: 81-82. 


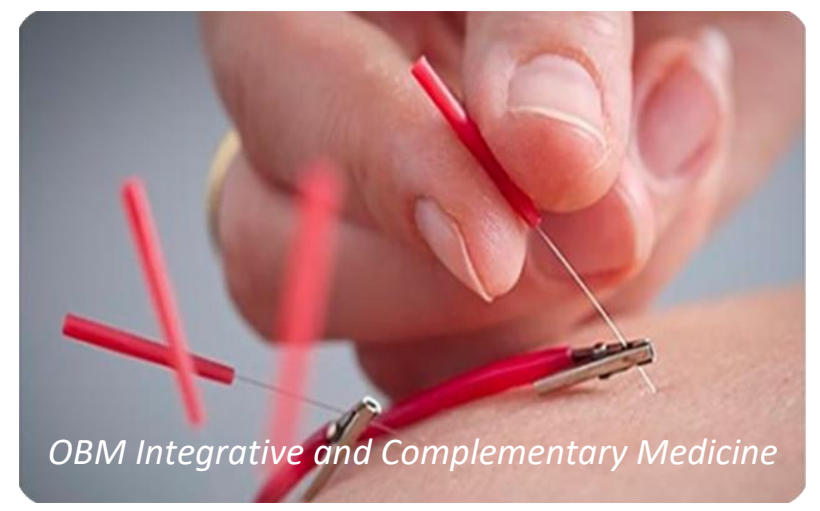

Enjoy OBM Integrative and Complementary Medicine by:

1. Submitting a manuscript

2. Joining in volunteer reviewer bank

3. Joining Editorial Board

4. Guest editing a special issue

For more details, please visit:

http://www.lidsen.com/journals/icm 